\title{
Prognostic value of tumour endothelial markers in patients with endometrial cancer
}

\author{
NICK A. BERSINGER ${ }^{1}$, BRIGITTE SCHNEIDER ${ }^{1}$, STEPHAN A. VORBURGER ${ }^{2}$, \\ SILKE JOHANN $^{1}$, DANIEL CANDINAS ${ }^{2}$ and MICHAEL D. MUELLER ${ }^{1}$ \\ Departments of ${ }^{1}$ Obstetrics and Gynaecology, and ${ }^{2}$ Visceral and Transplantation Surgery, \\ Inselspital, University Hospital and University of Berne, Switzerland
}

Received June 23, 2009; Accepted September 22, 2009

DOI: $10.3892 /$ ol_00000037

\begin{abstract}
Endometrial cancer is one of the more frequent and most lethal gynaecological cancer types. Since it occurs more frequently in elderly and overweight patients, a pre-operative staging method would be beneficial. The growth of solid neoplasms is always accompanied by neovascularisation. Tumour endothelial markers (TEMs) are a group of recently described endothelial cell surface markers that appear to be specific to neoplastic tissue. This study aimed to investigate the potential usefulness of TEM assessment in the endometrium by comparing the transcriptional expression of TEMs in the normal endometrium with endometroid adenocarcinoma tissue. Tissues were lysed and the RNA was extracted, assessed and reverse transcribed in one batch. Real-time quantitative PCR was performed for TEM-1, -2, -6, -7, -7r and -8. GAPDH, $\beta$-actin and ribosomal protein L13A (RPL13A) were used as control genes. TEM-8 showed the highest expression level in all of the groups. TEM-1 showed higher expression levels in the normal endometrium than in the tumour tissues. For the remaining TEMs, we found a higher expression in the cancer samples than in the normal endometria. Statistical significance of this difference was achieved for TEM-1, -2 and-7. No clear correlation was noted between the tumour stage and the level of TEM-1, -6 and -8 expression. Apart from TEM-6, the highest expression in FIGO I cancer stages was noted in the remaining TEMs. Our results showed that for most of these tumour endothelial markers, gene expression was slightly higher in the endometrial carcinoma tissue samples than in the endometrium of normal cycling women. However, with the possible exception of TEM-8 and -6, absolute expression levels were generally low, indicating that most TEMs may only be specifically expressed in a restricted number of cancer types (e.g., colorectal). Therefore, TEMs may not be useful in the context of endometrial cancer.
\end{abstract}

Correspondence to: Dr Nick A. Bersinger, Inselspital, DKF, Murtenstrasse 35, Berne CH-3010, Switzerland

E-mail: nick.bersinger@dkf.unibe.ch

Key words: tumour endothelial markers, endometrium, endometrial cancer

\section{Introduction}

Endometrial cancer is the most frequent gynaecological type of cancer. Hysterectomy with bilateral oophorectomy and pelvic with or without paraaortic lymphadenectomy are the primary therapeutic treatments available for endometrial cancer. Although the therapeutical value of lymphadenectomy is still under discussion, it is usually necessary to correctly stage endometrial cancer to determine whether or not adjuvant therapy is necessary. Since endometrial cancer more frequently occurs in elderly and overweight patients, the availability of a preoperative, non-surgical staging method would be beneficial for these patients. Such a method would reduce morbidity which occurs inherently with lymphadenectomy.

The growth of solid neoplasms is always accompanied by neovascularisation. Tumour cells appear to stimulate endothelial cell proliferation. Moreover, endothelial cells may have an indirect effect over the rate of tumour growth. Solid tumours are dependent on angiogenesis for growth when they reach a size of 2-3 $\mathrm{mm}$ (1). Tumour and normal endothelium are distinct at the molecular level. In order to identify whether molecular markers are differentially expressed in normal- and tumour-derived endothelium, St Croix et al performed serial gene expression analyses on human endothelial cells isolated from normal colonic mucosa or from colorectal tumours. The authors identified 46 transcripts, named tumour endothelial markers (TEMs), which were significantly up-regulated in tumour compared with normal endothelium. Nine (TEM-1 to -9) were investigated. TEMs are specific to tumour endothelial cells and are potentially involved in tumour angiogenesis. They are more specific to tumour cells than other endothelial markers similarly involved in angiogenesis, such as Von Willebrand factor or CD31 (2). Four of the TEMs (TEM-1, $-5,-7$ and -8 ) are located on the cell surface and, thus, would be accessible to pharmacological agents $(3,4)$. TEM- 5 appears to be a seven-pass G-protein-coupled transmembrane receptor, whereas TEM-1, -7 and -8 span the membrane once (3).

Several different TEMs have been identified in various, though mostly colorectal, cancer types. Most of the TEMs can be detected in normal, non-cancerous samples, but are also expressed at a higher level in tumour tissues. Only TEM-8 was almost absent in normal tissues while its expression levels were significantly raised in colon cancer tissues (5). No information 
Table I. Summary of tumour endothelial markers and primer characteristics.

\begin{tabular}{lllr}
\hline Marker & \multicolumn{1}{c}{ Name } & AB gene no. & Amplicon size (bp) \\
\hline TEM-1 & Endosialin, CD248 & Hs00535574_s1 & 81 \\
TEM-2 & RASD family member 2 & Hs00374755_m1 & 84 \\
TEM-6 & Tensin 3 & Hs00224228_m1 & 60 \\
TEM-7 & Plexin domain containing 1 & Hs00220723_m1 & 58 \\
TEM-7r & Plexin domain containing 2 & Hs00262350_m1 & 109 \\
TEM-8 & Anthrax toxin receptor 1 & Hs00216777_m1 & 67 \\
GAPDH & AP dehydrogenase & Hs99999905_m1 & 122 \\
$\beta$-actin & $\beta$-actin & Hs00242273_m1 & 93 \\
L13A & Ribosomal protein L13A & Hs01926559_g1 & 105 \\
PP14 & Glycodelin & Hs00171462_m1 & 109 \\
MMP-2 & Metalloproteinase 2 & Hs00234422_m1 & 93 \\
\hline
\end{tabular}

on the expression of TEMs in the endometrium is available in the literature.

This study aimed to investigate whether normal, eutopic endometrium expressed TEMs and to analyse whether this expression was more pronounced in endometrial cancer than in healthy, intra-uterine control tissues.

\section{Materials and methods}

Eutopic endometrium $(n=8)$ was sampled with a soft catheter (Pipelle de Cornier, Laboratoire CCD, France) from patients undergoing laparoscopic infertility investigations at the Department of Obstetrics and Gynaecology. Tumour tissue samples (endometrial cancers of various stages, $n=10$ ) were withdrawn from the Tumour Bank established at the University of Berne. Solid tissues (endometrium and carcinomata), previously stored in RNAlater (Sigma, USA) at $-80^{\circ} \mathrm{C}$ or $-150^{\circ} \mathrm{C}$ for the tumour tissues, were homogenised using a steel bead, lysed and extracted using a commercial procedure (SV Total RNA isolation system; Promega, USA) that included an on-column DNase digestion step before elution.

Different cell lines as well as colon cancer tissue from three patients were included as positive controls. The MCF-7 cell line was obtained from pleura effusion of breast adenocarcinoma of a 69-year-old female, and was known to express high levels of TEM-8 (6). The SW620 cell line was derived from lymph node metastasis of a colon adenocarcinoma of a 51-year-old male, while the line SW480 was established from primary colon cancer (7). CACO-2 and DLD-1 were similarly derived from colon adenocarcinomata $(8,9)$.

The cells were cultured in MEM (Iscove's modification with $25 \mathrm{mM}$ Hepes; Gibco Invitrogen, Scotland) containing fetal bovine serum $(10 \% \mathrm{v} / \mathrm{v})$ and antibiotics/antimycotic (Gibco) to confluence $\left(37^{\circ} \mathrm{C}, 5 \% \mathrm{CO}_{2}\right.$ in air). The adherent cells were then washed with phosphate-buffered saline and lysed directly on the plate with the lysis buffer provided in the SV-RNA extraction kit.

Concentration and purity of the RNA were determined by spectrophotometry at 260 and $280 \mathrm{~nm}$, and by calculating the ratio between the two values. RNA samples were selected for further investigation based on their quality as assessed by capillary electrophoresis (RNA 6000 Nano Labchip ${ }^{\circledR}$, Agilent Technologies, USA) and by their $260 / 280 \mathrm{~nm}$ ratio (>1.9).

A 300 ng RNA sample was reverse transcribed with the Archive ${ }^{\circledR}$ Kit (Applied Biosystems, USA) in one batch in an incubation of $10 \mathrm{~min}$ at $25^{\circ} \mathrm{C}$ and $60 \mathrm{~min}$ at $37^{\circ} \mathrm{C}$, and the resulting cDNA was stored at $-30^{\circ} \mathrm{C}$ until further use. Quantitative (real-time) polymerase chain reaction (PCR) was performed with TaqMan ${ }^{\circledR}$ primer/probes (Assay-on-demand ${ }^{\circledR}$, Applied Biosystems) for TEM-1, -2, -6, -7, -7r and -8. The PCR reactions were run on an ABI PRISM ${ }^{\circledR}$ SDS 7900 HT thermocycler (Applied Biosystems). GAPDH, $\beta$-actin and ribosomal protein L13A (RPL13A) were used as control or reference genes. Matrix metalloproteinase-2 (MMP-2) and glycodelin (PP14) were determined as well. Primer and TEM data are summarised in Table I.

\section{Results}

Among the six endothelial tumour markers investigated, TEM-1, -6 and -8 showed the highest expression level (per ng of reverse transcribed RNA) over all the groups of cells and tissues. The different positive controls (cell lines and biopsies of colon carcinomata) showed expression levels which varied from 0 to the level of GAPDH expression. The controls are shown in Table II as a percentage of the GAPDH expression level for that particular tumour marker.

In endometrium, TEM-1 showed a higher expression level (lower $\mathrm{Ct}$ value) in the normal healthy tissues than in the tumour samples. For all other TEMs, however, we found a marginally higher expression in the cancer samples than in the normal endometria. The raw $\mathrm{Ct}$ values are shown in Table III for the two groups of tissues. Statistical significance for the difference in gene expression between healthy and cancerous endometrium was achieved for TEM-1, -2 and -7 . The results were normalised against GAPDH, $\beta$-actin and L13A (Fig. 1).

For glycodelin the differential expression between the two groups of endometrium was much more pronounced, with the $\mathrm{Ct}$ difference at 6.84 after normalisation, corresponding to a 114-fold down-regulation in carcinoma compared to healthy tissue. No differential expression was observed for MMP-2. 
Table II. Gene expression levels for different tumour endothelial markers in human cell lines and biopsies of colon cancer tissue.

\begin{tabular}{|c|c|c|c|c|c|c|c|}
\hline & GAPDH & TEM-1 & TEM-2 & TEM-6 & TEM-7 & TEM-7r & TEM-8 \\
\hline \multicolumn{8}{|l|}{ Cell line } \\
\hline SW620 & 100 & 27.5 & 13.4 & 65.4 & 0.0 & 0.0 & 78.0 \\
\hline SW480 & 100 & 18.3 & 41.6 & 59.4 & 18.2 & 0.0 & 75.1 \\
\hline DLD-1 & 100 & 23.7 & 14.8 & 64.0 & 7.5 & 25.1 & 100.1 \\
\hline CACO-2 & 100 & 50.2 & 0.0 & 62.0 & 3.0 & 14.7 & 14.0 \\
\hline MCF-7 & 100 & 19.9 & 45.0 & 52.3 & 34.0 & 35.5 & 78.2 \\
\hline \multicolumn{8}{|c|}{ Colon cancer tissue } \\
\hline No. 504 & 100 & 4.8 & 0.0 & 45.1 & 0.0 & 5.3 & 7.7 \\
\hline No. 516 & 100 & 10.4 & 1.5 & 37.8 & 14.7 & 26.3 & 38.1 \\
\hline No. 564 & 100 & 32.6 & 0.0 & 37.8 & 16.5 & 22.8 & 35.4 \\
\hline
\end{tabular}

Values (given in \%) are derived from threshold cycle $(\mathrm{Ct})$ and normalised to expression of GAPDH=100\%.

Table III. Raw Ct values obtained in quantitative PCR for 6 tumour endothelial markers and 3 reference genes.

\begin{tabular}{|c|c|c|c|}
\hline $\begin{array}{l}\text { Gene } \\
\text { (Reference of TEM) }\end{array}$ & $\begin{array}{l}\text { Healthy endometrium } \\
\qquad(\mathrm{n}=8)\end{array}$ & $\begin{array}{l}\text { Endometrial cancer } \\
\qquad(\mathrm{n}=10)\end{array}$ & P-value \\
\hline \multicolumn{4}{|l|}{ Reference } \\
\hline GAPDH & $21.42 \pm 1.16$ & $21.35 \pm 1.47$ & NS \\
\hline$\beta$-Actin & $21.53 \pm 1.50$ & $21.43 \pm 0.85$ & NS \\
\hline L13A & $26.87 \pm 0.94$ & $27.16 \pm 1.05$ & NS \\
\hline \multicolumn{4}{|c|}{ Tumour endothelial markers } \\
\hline TEM-1 & $26.28 \pm 1.41$ & $27.97 \pm 1.22$ & 0.015 \\
\hline TEM-2 & $34.25 \pm 1.09$ & $32.28 \pm 1.53$ & 0.007 \\
\hline TEM-6 & $27.31 \pm 0.83$ & $26.70 \pm 0.82$ & NS \\
\hline TEM-7 & $30.26 \pm 1.16$ & $28.26 \pm 1.12$ & 0.002 \\
\hline TEM-7r & $30.06 \pm 0.99$ & $29.42 \pm 1.40$ & NS \\
\hline TEM-8 & $25.51 \pm 1.59$ & $25.46 \pm 1.58$ & NS \\
\hline \multicolumn{4}{|l|}{ Other genes } \\
\hline Glycodelin & $27.30 \pm 5.10$ & $34.18 \pm 1.09$ & $<0.001$ \\
\hline MMP-2 & $25.02 \pm 1.42$ & $25.83 \pm 1.84$ & NS \\
\hline
\end{tabular}

Values are means \pm SD. P-values were obtained by Student's t-test and are quoted as not significant (NS) if $>0.05$. MMP-2, metallopeptidase-2.

When the results for the endometrial tumour samples were analysed with respect to FIGO staging, no correlation between this stage and the levels of TEM-1, -6 and -8 expression was noted. The studied TEMs, with the exception of TEM-6, showed the highest expression in FIGO stage I. Only one tissue sample was assigned to be FIGO stage IV. Therefore, statistical analysis was not possible. However, the expression levels for the 6 investigated TEMs were lower in this sample than in the remaining TEMs which were expressed in FIGO stages I to III (data not shown).

\section{Discussion}

The production of TEM-8 by the MCF-7 cell line (6) was confirmed. This cell line also expressed the remaining
TEMs studied, and the same was the case for DLD-1. Table II shows the values in relation to GAPDH expression. The other colon adenocarcinoma-derived cell lines expressed the different TEMs to a varying extent, indicating the specificity of the assays and the cell lines, and thus validating this study. SW480/SW620 lines expressed high levels of TEM-6 and -8, but no or little TEM-7/-7r. CACO-2 expressed no TEM-2 and little TEM-7/-7r, but large levels of TEM-1 and -6 (Table II). In the 3 tested colon cancer tissue samples, TEM- 6 showed the highest expression level, followed by TEM- 8 (Table II), the latter confirming published data (5) and thus fulfilling the role of a positive control in this study. TEM-2 expression was low or undetectable.

We examined the possible expression of TEMs in human endometrium and endometrial cancer, specifically endometrial 


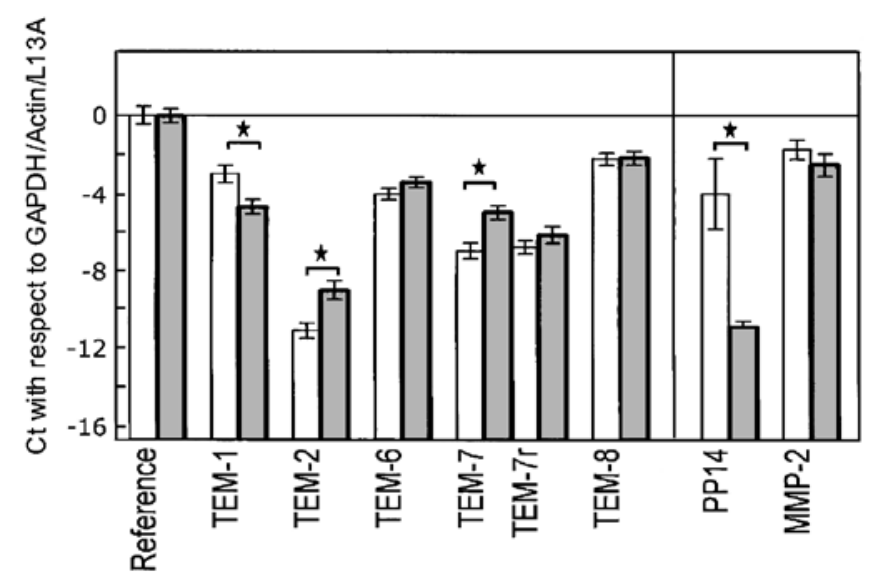

Figure 1. Gene expression levels of tumour endothelial markers (TEMs), glycodelin (PP14) and matrix metalloproteinase-2 (MMP-2) in healthy endometrial tissue (light bars, $n=8$ ) and endometrial carcinoma (dark bars, $n=10$ ). Values are expressed as mean $\pm \mathrm{SD}$ in $\mathrm{Ct}$ (i.e., relative to the copy number, in powers of 2 ) and normalised to the means for GAPDH, $\beta$-actin and ribosomal protein L13A (reference genes). The base line (-16.7) corresponds to the absence of the QPCR signal for the reference genes after 40 cycles. *Statistically significant differences $(\mathrm{P}<0.05$, Student's t-test)

adenocarcinoma, as performed by Davies et al with human breast cancer (6). The authors concluded that elevated levels of TEM-1, -7r and -9 (but not TEM-2, -4, -5, -6 and -7) are associated with either nodal involvement and/or disease progression, which may therefore have a prognostic value in breast cancer. Furthermore, the authors showed that TEMs appeared to be expressed in normal tissues as well. In their study, TEM-7r and -8 were significantly raised in breast cancer tissues compared with normal background tissues (10). In contrast, in our study, TEM-2 and -7 were significantly raised in endometrial cancer tissues compared with normal endometrium from healthy women. Rmali et al found that TEM-1, -7, -7r and -8 were significantly raised in colon cancer tissues compared with normal background tissues from the same patients. The same TEMs showed an association with both nodal involvement and disease progression (5). We did not repeat these investigations but have used breast cancer tissue for validation of our QPCR setup. TEM-8 was reported to be raised in breast and colon cancer tissues $(5,10,11)$. However, as regards the endometrium, we did not observe a significantly increased TEM- 8 gene expression in cancer tissue compared to healthy tissue. This indicates that TEM-8 shows a certain level of tissue specificity independent of the presence of cancer. Glycodelin (PP14) was shown to be negatively associated with ovarian cancer (12), i.e., it is a marker of differentiation which is lost in advanced cancer stages. A large fraction of ovarian cancers are of the endometroid type. In this study, glycodelin gene expression was determined and found to be strongly decreased in cancerous compared to healthy endometrium, which is in agreement with the previously mentioned report (12), thus validating the selection of our tissue samples. Moreover, glycodelin was found to reduce proliferation of endometrial carcinoma cells in vitro (13). MMP-2 expression, on the other hand, did not differ between the two tissue types, as confirmed by a recent report (14). In a more recent publication, MMP-2 expression was found to be lower in endometrial cancer than in endometriotic or healthy proliferative endometrial tissue (15).

With the exception of the known up-regulation of TEM-8 at the mRNA and protein levels in endothelial cells by interleukin-1 (16), the role of TEMs in tumour-associated angiogenesis and the factors which are able to regulate the expression of TEMs in human endothelial and cancer cells are unknown. The dependence of neoplasms on neovascularisation was previously identified and has subsequently led to substantial research efforts on tumour angiogenesis. Folkman et al described a tumour angiogenesis factor (TAF) which was isolated from human and animal tumours, and which was not found in normal tissues, with the exception of placenta. TAF was shown to stimulate the rapid formation of new capillaries in animals $(1,17)$. There are many factors (soluble, membrane-bound, biomechanical) which stimulate angiogenesis in normal and tumour tissues, as well as other factors which inhibit tumour angiogenesis (18). Angiogenesis normally occurs during fetal growth and development, but rarely occurs in adults, except during the ovarian cycle (corpus luteum formation) and in physiological repair processes such as wound healing (19-21). Focusing on TEM-1 to -9, St Croix et al showed in their analysis by in situ hybridization that the expression of TEM transcripts were associated with the endothelium of cancer types in the corpus luteum and granulation tissue of healing wounds, with the exception of TEM-8 which was not detectable in the corpus luteum (2). Furthermore, Carson-Walter et al identified the counterparts of TEM-1, -5, -7, -7r and -8 in mice (3).

The case numbers in our study are small. Consequently, further investigation on the specificity and significance of TEMs in endometrial and other gynaecological cancer types should be undertaken with larger sample numbers. The role of endothelial products at the protein level should also be investigated. Anti-TEM antibodies are commercially available for some but not all TEMs studied here, and for these a specific immunoassay (e.g., ELISA) could be developed for the quantitative expression of TEMs at the protein level. The antibodies can also be used to show by immunohistochemistry whether epithelial and/or stromal cells would express TEMs. Davies et al did not detect any TEM-8 in the MCF-7 cell line (6). The human endometrium is one of the few adult tissues that develops new capillaries from existing microvessels, which then undergo maturation and remodelling. This process is regulated primarily by the circulating steroids oestrogen and progesterone $(22,23)$. If development in a sensitive immunoanalytical detection method for TEMs at the protein level occurs, the expression of TEMs in the different stages of the menstrual cycle may be analysed and compared. Moreover, if the expression of TEMs is dependent on sex hormones, it would be interesting to investigate whether this influence is direct or secondary, as in the case of the up-regulation of the vascular endothelial growth factor (VEGF) receptor Flk-1/ KDR by estradiol, secondary to the up-regulation of VEGF expression (24).

\section{Acknowledgements}

We thank Professor Rolf Jaggi for his help with the PCR, Daniel Müllener for providing the tumour tissue samples from the University of Berne Tumour Bank and Anne Vaucher, 
Andrea Oberli and Anne Baltzer for their help with technical laboratory issues.

\section{References}

1. Folkman J: Tumor angiogenesis: Therapeutic implications. N Engl J Med 285: 1182-1186, 1971.

2. St Croix B, Rago C, Velculescu V, et al: Genes expressed in human tumor endothelium. Science 289: 1197-1201, 2000.

3. Carson-Walter EB, Watkins DN, Nanda A, Vogelstein B, Kinzler KW and St Croix B: Cell surface tumour endothelial markers are conserved in mice and humans. Cancer Res 61: 6649-6655, 2001.

4. Nanda A and St Croix B: Tumour endothelial markers: new targets for cancer therapy. Curr Opin Oncol 16: 44-49, 2004.

5. Rmali KA, Puntis MC and Jiang WG: Prognostic values of tumor endothelial markers in patients with colorectal cancer. World J Gastroenterol 11: 1283-1286, 2005.

6. Davies G, Rmali KA, Watkins G, Mansel RE, Mason MD and Jiang WG: Elevated levels of tumour endothelial marker- 8 in human breast cancer and its clinical significance. Int J Oncol 29: 1311-1317, 2006.

7. Leibovitz A, Stinson JC, McCombs WB, McCoy CE, Mazur KC and Mabry ND: Classification of human colorectal adenocarcinoma cell lines. Cancer Res 36: 4562-4569, 1976.

8. Fogh J: Submission of Caco-2 cell line to the American Type Culture Collection (ATCC). J Natl Cancer Inst 58: 221-226, 1977.

9. Dexter DL, Barbosa JA and Calabresi P: N,N-dimethylformamideinduced alteration of cell culture characteristics and loss of tumorigenicity in cultured human colon carcinoma cells. Cancer Res 39: 1020-1025, 1979.

10. Davies G, Cunnick GH, Mansel RE, Mason MD and Jiang WG: Levels of expression of endothelial markers specific to tumourassociated endothelial cells and their correlation with prognosis in patients with breast cancer. Clin Exp Metastasis 21: 31-37, 2004.

11. Rmali KA, Watkins G, Harrison G, Parr C, Puntis MCA and Jiang WG: Tumour endothelial marker 8 (TEM-8) in human colon cancer and its association with tumour progression. Eur J Surg Oncol 30: 948-953, 2004.
12. Mandelin E, Lassus H, Seppala M, et al: Glycodelin in ovarian serous carcinoma: association with differentiation and survival. Cancer Res 63: 6258-6264, 2003.

13. Koistinen H, Seppala M, Nagy B, Tapper J, Knuutila S and Koistinen R: Glycodelin reduces carcinoma-associated gene expression in endometrial adenocarcinoma cells. Am J Obstet Gynecol 193: 1955-1960, 2005.

14. Bogusiewicz M, Stryjecka $M$ and Rechberger T: Activity of matrix metalloproteinases -2 and -9 (MMP-2 and MMP-9) and content of their tissue inhibitors in endometrial cancer - a preliminary study. Ginekol Pol 78: 366-372, 2007.

15. Shaco-Levy R, Sharabi S, Benharroch D, Piura B and SionVardy N: Matrix metalloproteinases -2 and -9 , E-cadherin and beta-catenin expression in endometriosis, low-grade endometrial carcinoma and non-neoplastic eutopic endometrium. Eur J Obstet Gynecol Reprod Biol 139: 226-232, 2008.

16. Rmali KA, Al-Rawi MA, Parr C, Puntis MC and Jiang WG: Up-regulation of tumour endothelial marker- 8 by interleukin- $1 \beta$ and its impact in IL-1 $\beta$ induced angiogenesis. Int J Mol Med 14: 75-80, 2004

17. Folkman J, Merler E, Abernathy $\mathrm{C}$ and Williams G: Isolation of a tumor factor responsible for angiogenesis. J Exp Med 133: 275-288, 1971.

18. Papetti M and Herman IM: Mechanisms of normal and tumourderived angiogenesis. Am J Physiol Cell Physiol 282: 947-970, 2002.

19. Folkman J and Klagsbrun M: Angiogenic factors. Science 235: 442-447, 1987.

20. Reynolds L, Killilea SD and Redmer DA: Angiogenesis in the female reproductive system. FASEB J 6: 886-892, 1992.

21. Reynolds L and Redmer DA: Expression of the angiogenic factors, basic fibroblast growth factor and vascular endothelial growth factor in the ovary. J Anim Sci 76: 1671-1681, 1998.

22. Gargett CE and Rogers PA: Human endometrial angiogenesis. Reproduction 121: 181-186, 2001.

23. Krikun G, Schatz F and Lockwood CJ: Endometrial angiogenesis: from physiology to pathology. Ann NY Acad Sci 1034: 27-35, 2004.

24. Hervé MA, Meduri G, Petit FG, Domet TS, Lazennec G, Mourah S and Perrot M: Regulation of the vascular endothelial growth factor (VEGF) receptor Flk-1/KDR by estradiol through VEGF in uterus. J Endol 188: 91-99, 2006. 